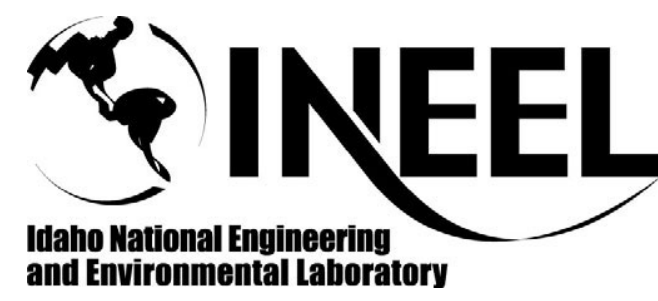

INEEL/CON-04-01592

PREPRINT

The Safety And Tritium Applied Research (STAR) Facility: Status-2004

\author{
R. A. Anderl \\ G. R. Longhurst \\ R. J. Pawelko \\ J. P. Sharpe \\ S. T. Schuetz \\ D. A. Petti
}

September 12-17, 2004

$7^{\text {th }}$ International Conference On Tritium Science
And Technology

This is a preprint of a paper intended for publication in a journal or proceedings. Since changes may be made before publication, this preprint should not be cited or reproduced without permission of the author. This document was prepared as an account of work sponsored by an agency of the United States Government. Neither the United States Government nor any agency thereof, or any of their employees, makes any warranty, expressed or implied, or assumes any legal liability or responsibility for any third party's use, or the results of such use, of any information, apparatus, product or process disclosed in this report, or represents that its use by such third party would not infringe privately owned rights. The views expressed in this paper are not necessarily those of the U.S. Government or the sponsoring agency. 


\title{
THE SAFETY AND TRITIUM APPLIED RESEARCH (STAR) FACILITY: STATUS-2004
}

\author{
R. A. Anderl, G. R. Longhurst, R. J. Pawelko, J. P. Sharpe, S. T. Schuetz, D. A. Petti \\ Fusion Safety Program \\ Idaho National Engineering and Environmental Laboratory \\ P. O. Box 1625, Idaho Falls, ID 83415-7113 \\ (208)533-4153, raa@inel.gov \\ Paper D2-I2 presented at \\ $7^{\text {th }}$ International Conference on Tritium Science and Technology \\ TRITIUM 2004 \\ September 12-17, 2004 \\ Kongresshaus, \\ Baden-Baden, Germany
}

To be published in Fusion Science and Technology 


\title{
THE SAFETY AND TRITIUM APPLIED RESEARCH (STAR) FACILITY: STATUS-2004
}

\author{
R. A. Anderl, G. R. Longhurst, R. J. Pawelko, J. P. Sharpe, S. T. Schuetz, D. A. Petti \\ Fusion Safety Program \\ Idaho National Engineering and Environmental Laboratory \\ P. O. Box 1625, Idaho Falls, ID 83415-7113 \\ (208)533-4153,raa@inel.gov
}

The Safety and Tritium Applied Research (STAR) Facility, a US DOE National User Facility at the Idaho National Engineering and Environmental Laboratory (INEEL), comprises capabilities and infrastructure to support both tritium and non-tritium research activities important to the development of safe and environmentally friendly fusion energy. Research thrusts include (1) interactions of tritium and deuterium with plasma-facingcomponent (PFC) materials, (2) fusion safety issues [PFC material chemical reactivity and dust/debris generation, activation product mobilization, tritium behavior in fusion systems], and (3) molten salts and fusion liquids for tritium breeder and coolant applications. This paper updates the status of STAR and the capabilities for ongoing research activities, with an emphasis on the development, testing and integration of the infrastructure to support tritium research activities. Key elements of this infrastructure include a tritium storage and assay system, a tritium cleanup system to process glovebox and experiment tritiated effluent gases, and facility tritium monitoring systems.

\section{INTRODUCTION}

Initial plans for the Safety and Tritium Applied Research (STAR) Facility were presented previously [1]. Designated a US Department of Energy National User Facility at the Idaho National Engineering and Environmental Laboratory (INEEL), STAR has the mission to provide the laboratory infrastructure for the fusion community to study tritium science and technology issues important to the development of safe and environmentally friendly fusion energy. Both tritium and non-tritium fusion safety research is pursued along three key research thrust areas: (1) plasma-material interactions (PMI) of plasma-facing components (PFC) materials exposed to energetic tritium and deuterium, (2) fusion safety issues related to PFC material chemical reactivity and dust/debris generation, activation product mobilization, and tritium behavior in fusion systems, and (3) molten salts and fusion liquids for tritium breeder and coolant applications.

The purpose of this paper is to provide the status of STAR development activities as of September, 2004. This includes an overview of the STAR facility and its capabilities for ongoing and future research activities. A more detailed presentation is dedicated to the installation and testing of infrastructure to support tritium operations. Key elements of this infrastructure include a tritium storage and assay system (SAS), a tritium cleanup system (TCS) to process glovebox and experiment tritiated effluent gases, and facility tritium monitoring systems.

\section{STAR FACILITY DESCRIPTION}

STAR is classified as a Radiological facility, and it is restricted to a facility total tritium inventory of less than $16,000 \mathrm{Ci}$ of tritium, the threshold limit for a Category-3 Nuclear Facility [2]. To assure compliance with this limit, the tritium inventory is administratively controlled to $15,000 \mathrm{Ci}$.

\section{II.A. General Layout and Overview}

As illustrated in Figure 1, the STAR facility comprises a multi-room complex in two adjoining buildings, TRA-666A and TRA-666, at the Test Reactor Area (TRA) of the INEEL. Providing about $400 \mathrm{~m}^{2}$ of working area for bench scale experiments and engineering tests, the facility is equipped with:

(1) conventional laboratory infrastructure consisting of 110-, 208-, and 480-VAC electrical power, demineralized water, raw water, pressurized air lines, floor drains, HVAC (heating, ventilating and air conditioning) systems that provide once-through conditioned air to the laboratory rooms, class-A hoods, inert-gas gloveboxes, a fire alarm system and heat-activated wet-pipe sprinkler system, and a distributed Ethernet network;

(2) tritium infrastructure consisting of inert-gas gloveboxes, a tritium cleanup system to process glovebox and experiment tritiated gaseous effluent, a tritium storage and assay system, a glovebox purge gas system and tritium monitoring instrumentation.

TRA-666A includes an office/entry room (Rm-101) and two laboratory rooms (Rm-102 and 103) used to support general fusion safety research activities [3] that historically have not involved the use of tritium or only 


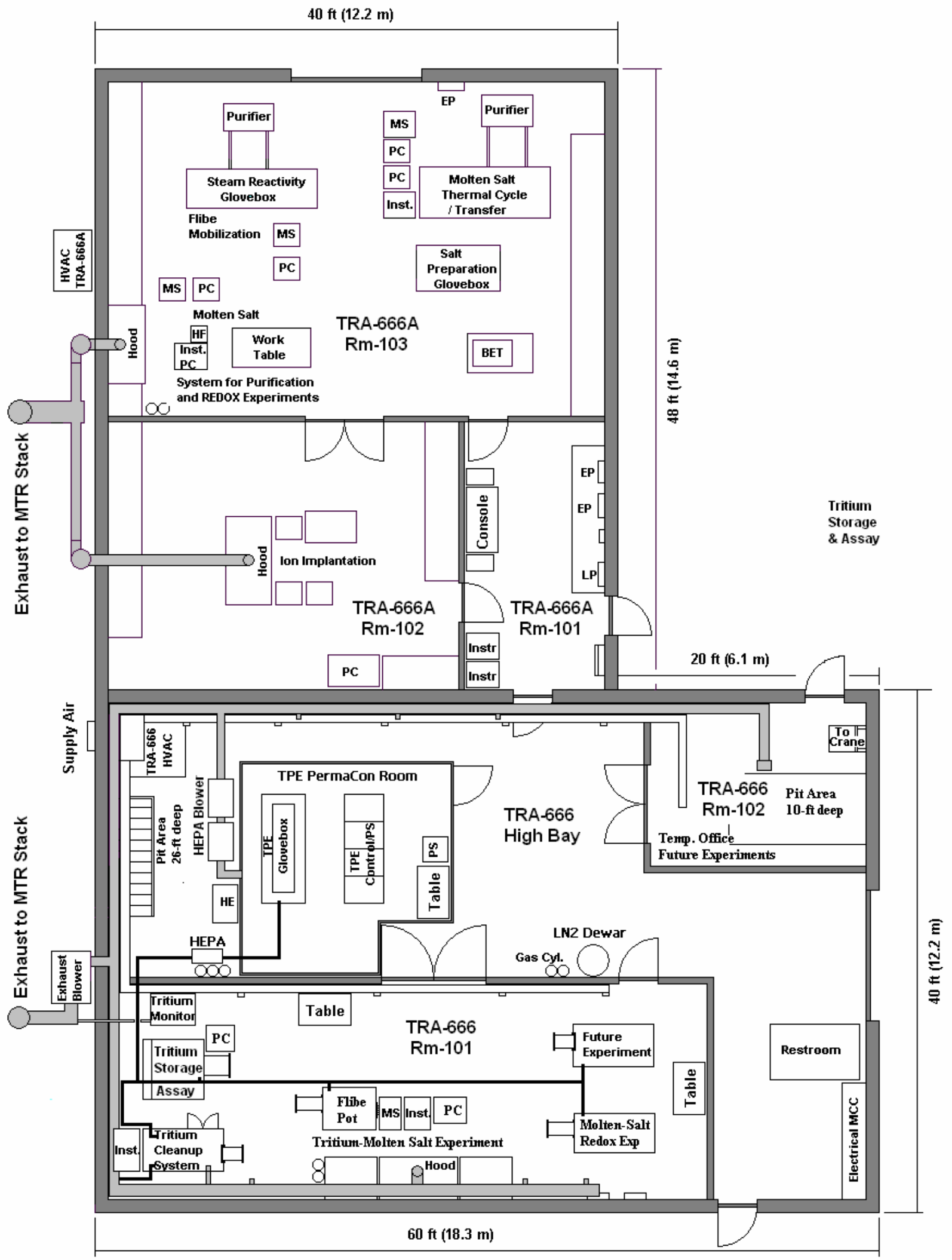

Figure 1. Schematic floor plan layout of the STAR facility (September, 2004) 
small quantities of tritium. Currently, Rm-102 houses a deuterium ion implantation system for PMI studies. Examples of past work with this system are found in References [4,5]. Rm-103 houses experimental capabilities in two inert gas gloveboxes and in a class-A hood to support preparation, purification and testing of fluoride salt mixtures (currently the $2 \bullet \mathrm{LiF}_{2}-\mathrm{BeF}_{2}$ mixture called Flibe) for molten salt experiments. These experiments, conducted as part of the Japan/US Program on Irradiation Tests for Fusion Energy Research (JUPITER-II) [6,7], investigate REDOX control chemistry and tritium behavior issues important to use of Flibe for tritium breeder applications. Examples of recent work are found in References [8,9]. This room also houses an inert gas glovebox that is equipped with an experimental system to investigate chemical reactivity of PFC materials exposed to steam [10,11]. A BET (Brunauer, Emmett, Teller) system is also set up in Rm. 103 for specific surface area measurements of dusts, powders and porous materials. This system has been used to characterize dusts from fusion devices [12,13]. Rm. 103 has also been equipped with systems to investigate mobilization of fusion relevant materials exposed to air and steam $[14,15]$. These capabilities will continue to support our fusion safety research activities.

TRA-666 comprises a High Bay with overhead crane, two laboratory rooms, Rm-101 and 102, and two pits on opposite ends of the High Bay. A PermaCon structure [16] is installed in the High Bay to provide a ventilated, environment for the Tritium Plasma Experiment (TPE) $[17,18]$ that was moved from the Los Alamos National Laboratory (LANL) to the INEEL. TPE comprises a linear plasma device enclosed inside a glovebox and associated power supplies and control instrumentation outside the glovebox. This system provides a unique linear plasma capability for PMI studies of PFC materials exposed to intense plasmas. Rm-101 houses the key elements of the tritium infrastructure, additional gloveboxes for future experiments that use tritium, and an experimental setup that was used to investigate hydrogen transport behavior in Flibe [9]. At the present time, Rm. 102 serves as a temporary office room with capabilities to allow future experimental setups.

\section{II.B. Tritium Infrastructure in the STAR Facility}

TRA-666 is equipped with the capabilities and infrastructure to support current and planned research that involves the use of tritium. Design of this infrastructure is based on the philosophy of containment and confinement, where tritium is contained in leak-tight experimental and process systems located inside gloveboxes that, in turn, provide secondary barriers to confine accidental tritium release from the primary containment [2]. In addition, the tritium-containing gloveboxes are typically located inside ventilated rooms that provide a measure of tertiary confinement in the case of an accidental release from a glovebox. Some experiments involving small quantities of tritium may be done in a ventilated environment like the class-A hood.

As illustrated in Figure 1, TRA-666 is equipped with an HVAC system that is separate from that for TRA666A. The TRA-666 system services Rooms 101 and 102 and the High Bay. It provides once-through ventilation in Rooms 101 and 102 at a rate of about 6 air changes per hour. Inlet air is supplied to each room by ducts located near the ceilings of the rooms, and outlet air is exhausted through hoods and/or duct inlet grilles on the opposite walls. Rm. 101 is maintained at a pressure slightly negative ( $\sim 0.3$ mbar) with respect to the High Bay that is maintained at a pressure close to that outside the building.

The TPE PermaCon room is serviced by a HEPAfiltered blower that provides 6-10 room air changes per hour with outlet flow to the TRA-666 exhaust duct leg in the High Bay. The High-Bay exhaust duct leg merges with the exhaust duct leg from Rm-101, and the TRA-666 exhaust blower pumps the combined airflow. This enclosure and ventilation approach was selected for TPE because of specific beryllium and tritium contamination issues with some system components.

\section{II.B.I. Tritium Cleanup System}

Gaseous tritiated effluent from STAR gloveboxes and associated experiment systems is processed by the TCS located in a ventilated enclosure in TRA-666, Rm101. Figure 2 provides a flow schematic for the system that was fabricated by M. Braun USA, Stratham, NH.

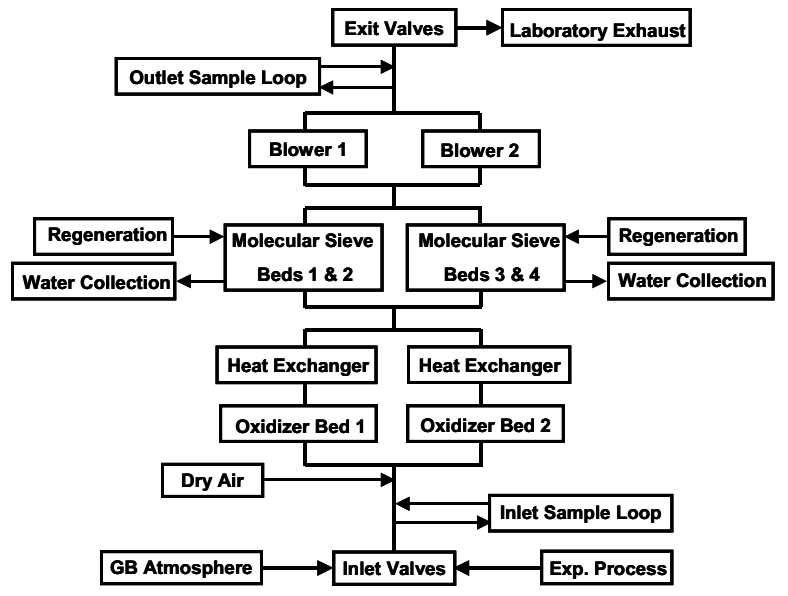

Figure 2. Flow schematic for the STAR TCS.

Operating in a single-pass mode, the TCS combines flows from the glovebox atmospheres and the experiments at the TCS inlet valves and exhausts the processed gas stream at the outlet valves to the laboratory exhaust. Typically, the glovebox atmosphere gas is inert $\left(\mathrm{N}_{2}\right.$ or Ar with trace 
tritium and air, nominal flow rate of $1-40 \mathrm{~L} / \mathrm{min}$ per glovebox) and the experiment process gas is inert with higher hydrogen or tritium concentrations (nominal flow rate much less than $1 \mathrm{~L} / \mathrm{min}$ ). Dry air is introduced upstream of the catalyst/oxidizer beds to ensure complete oxidation of hydrogen species.

As illustrated in Figure 2, the TCS design is based on conventional technology in which tritiated gaseous species in the flow stream are oxidized to tritiated water on heated oxidizer beds, and the tritiated water is removed from the process stream by adsorption on molecular sieve beds. Specifically, the STAR TCS consists of two oxidizer beds; two in-line heat exchangers; two molecular sieve bed pairs; two blowers; interconnecting plumbing and isolation valves; diagnostics on inlet and outlet sample loops to measure tritium concentrations, gas flow rates and system pressures; and moisture sensors between each molecular sieve bed pair to measure moisture breakthrough for the first bed. The inlet sample loop is also equipped with a hydrogen sensor. During normal operation, the user selects one of two catalyst beds, one of two molecular sieve bed pairs, and one of two blowers, so the TCS is equipped with redundancy for each of these critical components. Both manual and automatic modes of TCS operation are achieved via a control system that uses a Siemens Programmable Logic Controller (PLC). User control of the TCS operation is accomplished by a PC interface to the PLC via a Siemens WinCC graphical user interface (GUI) and associated control and data acquisition software. Figure 3 is a photo of the TCS as configured inside a ventilated glovebox enclosure

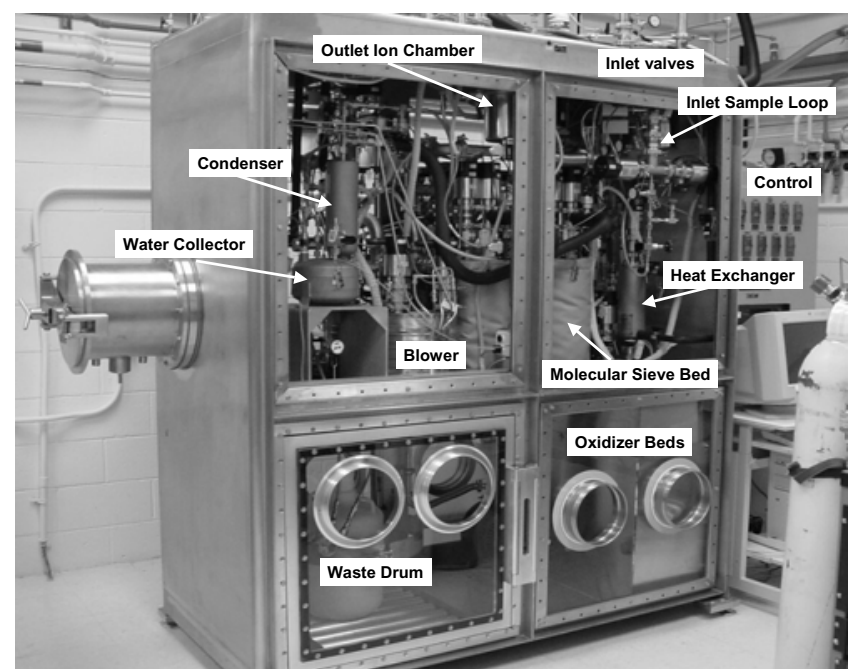

Figure 3. Photo of STAR TCS system

Each oxidizer bed is filled with $\sim 18 \mathrm{~kg}$ of BASF-R0$25 / 50-0.5 \%$ Pd catalyst material. With $0.5 \mathrm{wt} \% \mathrm{Pd}$ on an $\mathrm{Al}_{2} \mathrm{O}_{3}$ carrier, this catalyst can be used at temperatures up to $600^{\circ} \mathrm{C}$. In our application, the oxidizer beds are operated at $200^{\circ} \mathrm{C}$ for routine operation and at $450^{\circ} \mathrm{C}$ if the input stream from a specific experiment or process is suspected to contain substantial quantities of tritiated hydrocarbons. Bed design routes the incoming gas through a pre-heat zone before it enters the catalyst bed to ensure uniform and optimum hydrogen conversion (oxidation) efficiency in the bed. A clean bed has a pressure drop of $10 \mathrm{mbar}$ and can operate with a flow rate up to $1000 \mathrm{~L} / \mathrm{min}$.

Each molecular sieve bed is filled with a binary composition of adsorbent material, $1.1 \mathrm{~kg}$ of Type $4 \mathrm{~A}$ and $8.9 \mathrm{~kg}$ of Type $13 \mathrm{X}$ molecular sieve. At full saturation, water capacity is $\sim 2.5 \mathrm{~kg}$ of water per bed. As shown in Figure 2, each molecular sieve bed can be regenerated insitu when the inter-bed moisture sensor indicates breakthrough of the primary molecular sieve bed. During this process, a dry $\mathrm{N}_{2}$ gas flows in reverse direction through a bed heated to $250^{\circ} \mathrm{C}$, and the released water is captured in a water collector for ultimate transfer to a waste drum filled with a stabilizing medium. A clean bed has a pressure drop of 10 mbar and can operate with a flow rate up to $1000 \mathrm{~L} / \mathrm{min}$.

A mass-spectrometric (MS) approach employing hydrogen instead of tritium was used to evaluate the hydrogen conversion/removal performance of a test sample of Pd catalyst material, an oxidizer bed and the TCS. As shown in Figure 4, the technique employed a quadrupole mass spectrometer with a pressure-reduction sampling valve to measure the composition of a gas stream input to a test item and that exiting the test item. Valve manipulation enabled the measurement of the inlet gas composition by directing the flow through the bypass around the test specimen. The inlet gas stream comprised $\mathrm{N}_{2}, \mathrm{H}_{2}$ and $\mathrm{O}_{2}$ of different concentrations and flow rates by mixing the gases shown in the figure. This approach allows relative QMS peak-height measurements of M2 for $\mathrm{H}_{2}, \mathrm{M} 32$ for $\mathrm{O}_{2}$ and $\mathrm{M} 28$ for $\mathrm{N}_{2}$ to be used to evaluate the performance of the test item. Computation of the test item hydrogen decontamination factor (DF) is then given by (M2:M28)In/(M2/M28)Out, where (M2:M28)In $\{$ Out\} are peak-height ratios measured for the inlet and outlet streams, respectively. The hydrogen removal efficiency is then given by $(1-1 / \mathrm{DF}) \times 100 \%$.

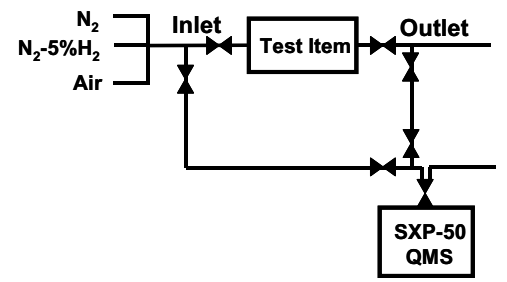

Figure 4. Mass spectrometric measurement arrangement to evaluate performance of test item.

Figure 5 shows one performance measurement for a test item consisting of $116 \mathrm{~g}$ of Pd catalyst material in a 150 -cc stainless steel cylinder heated from 25 to $130^{\circ} \mathrm{C}$. 
Inlet gas flow was $0.4 \mathrm{~L} / \mathrm{min}$ and the $\mathrm{H}_{2}$ concentration was $4 \%$. Results show a $\mathrm{H}_{2}$ removal efficiency of $11 \%$ at $25^{\circ} \mathrm{C}$ and an efficiency increasing to $99.9 \%$ as the bed temperature is raised to $130^{\circ} \mathrm{C}$. The results also show the increase in the M18:M28 ratio as the temperature is increased, indicating oxidation of elemental $\mathrm{H}_{2}$ to $\mathrm{H}_{2} \mathrm{O}$. In follow-on tests with a total flow rate of $8 \mathrm{~L} / \mathrm{min}$, the removal efficiency was at least $99.8 \%$ for this test item.

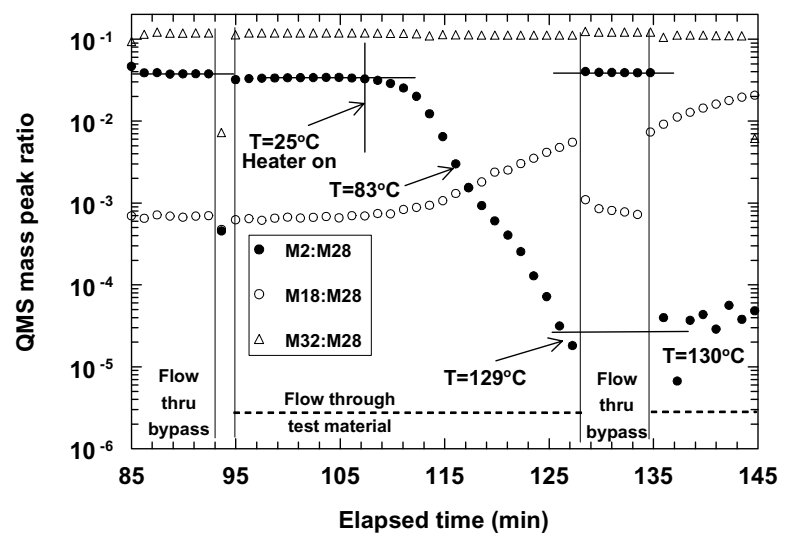

Figure 5. QMS data for test of Pd catalyst (116 g).

Using the same flow and QMS arrangement shown in Figure 4, single-pass performance test measurements were made for one TCS oxidizer bed and for the entire TCS system comprising an oxidizer bed and a pair of molecular sieve beds. The last test was repeated using the second oxidizer bed to assure performance of the TCS for all key components. For the individual oxidizer bed tests [gas flow rates of 3-7 L/min, $\mathrm{H}_{2}$ concentrations from 0.8 to $5 \%$, and a bed temperature of $300^{\circ} \mathrm{C}$ ], the observed performance efficiency was better than $99.9 \%$. For the TCS integrated system tests [flow rates from 10-30 $\mathrm{L} / \mathrm{min}, \mathrm{H}_{2}$ concentration from 0.6 to $4 \%$, and oxidizer bed temperatures of $450^{\circ} \mathrm{C}$ ], the performance efficiency was better than $99.99 \%$. Subsequent TCS integrated tests with the oxidizer bed at $200^{\circ} \mathrm{C}$ confirmed the high $\mathrm{H}_{2}$ removal efficiency for single-pass TCS operation of the TCS. This single-pass performance is expected to be sufficient to maintain annual tritium release to the environment less than $200 \mathrm{Ci}$ for normal operation. In the event of a large accidental release to a glovebox, the glovebox will be isolated, and the atmosphere will be slowly processed to maintain acceptable tritium releases to the environment.

\section{II.B.II. Tritium Storage and Assay System}

A key element of the tritium infrastructure is the Tritium SAS that will be used to store, assay and dispense tritium for experiment use. As shown in Figure 6, the Tritium SAS comprises the following: a vacuum manifold equipped with electro-pneumatic and manual valves, 3.8-L and 0.15-L standard volumes, two 47-g depleted uranium (DU) beds for storing tritium, capacitance manometer pressure sensors, Type-K temperature sensors, a beta-scintillation detector for tritium measurements, a metal bellows pump, an oil-free pumping station, a quadrupole mass spectrometer and precision leaks for gas analysis. All parts of the arrangement inside the dashed line of the figure are located inside an argon-purged glovebox. The vacuum pumping equipment is located beneath the floor of the glovebox, and it is surrounded by a ventilated enclosure. A PC is used to operate the SAS via Field Point interface and a LabView-based control and data acquisition program. Tritium assay is based on accurate pressure-volume-temperature (PVT) and beta scintillation detector measurements. A photo of the SAS assembly in STAR is shown in Figure 7. In a companion paper, Longhurst et al. [19] describes the SAS in more detail and presents the results of calibration measurements for system pressure sensors and volumes and the results of initial performance testing with hydrogen.

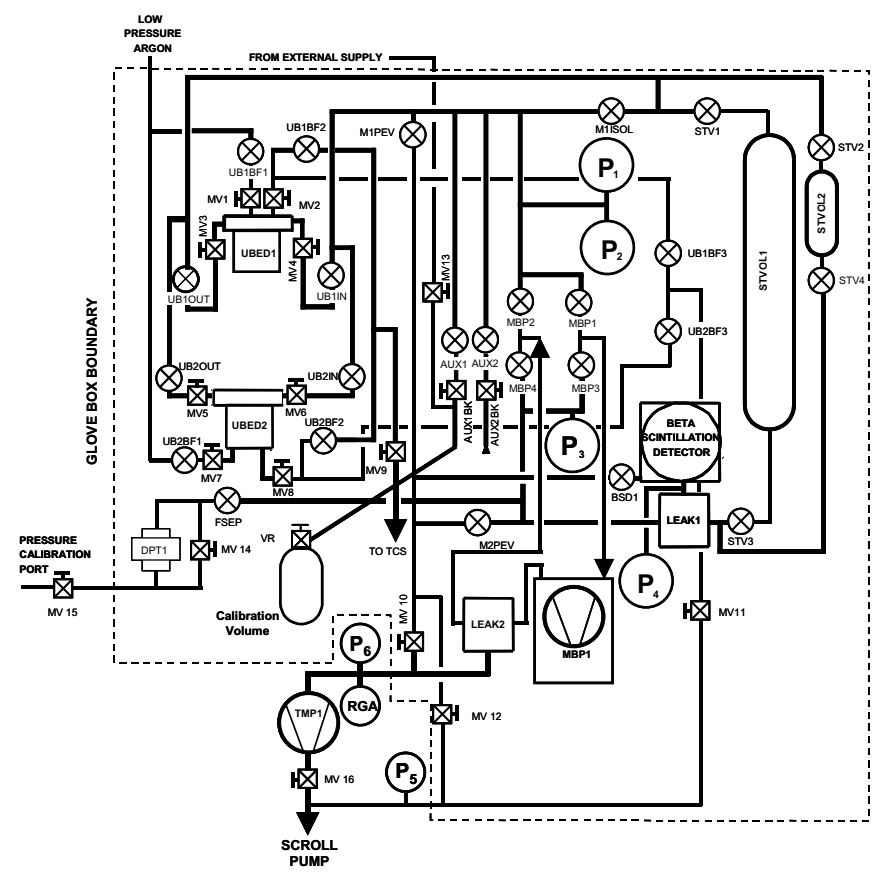

Figure 6. Schematic illustration of the Tritium Storage and Assay System for STAR.

\section{II.B.III. Glovebox Gas Purge and TCS Integration}

Gloveboxes for tritium use in STAR are maintained under a purged, inert atmosphere to keep tritium and hydrogen concentrations low in the glovebox atmosphere. Typically, the SAS glovebox is maintained with an $\mathrm{Ar}$ atmosphere, supplied from a pressure-regulated, compressed gas cylinder of UHP Ar. Other gloveboxes are supplied with pressure-regulated dry nitrogen from a combination LN2 Cryogenic Dewar and compressed gas cylinder supply station. This supply station is located in the High Bay of TRA-666 and it feeds a gas manifold that 


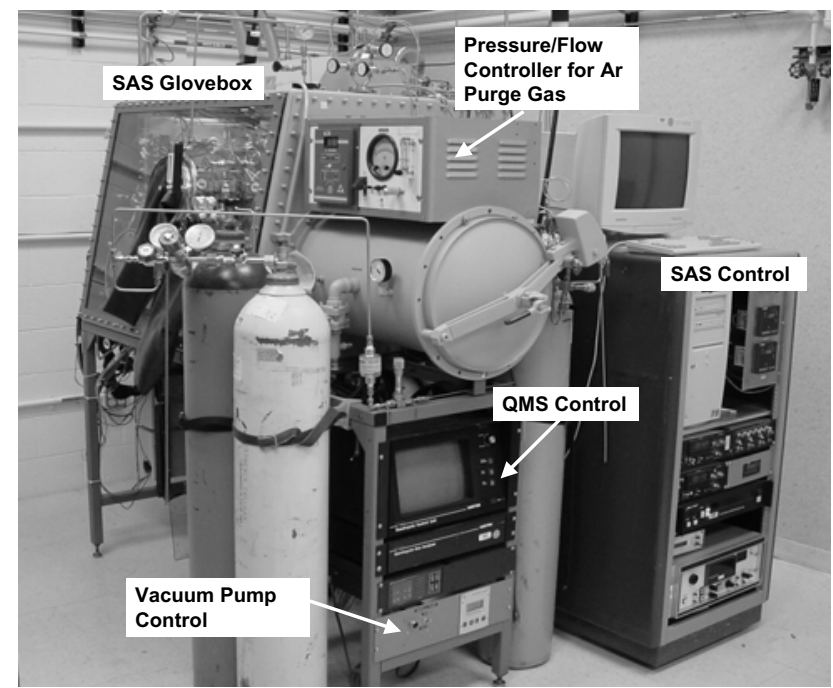

Figure 7. Setup of the Tritium Storage and Assay System.

is distributed around the inside of Room 101 with one leg servicing the TPE PermaCon structure. These regulated gas supplies are used in combination with glovebox pressure control devices to maintain the interior glovebox pressure slightly negative $(\sim-0.3 \mathrm{mbar})$ with respect to ambient room pressure. The pressure/flow controller, originally fabricated at LANL for tritium gloveboxes, is equipped with a differential pressure gauge, isolation valves, gas flow regulator, interconnecting gas manifold and control circuitry to maintain accurate delta-P for the glovebox atmosphere and to control the gas purge rate through the glovebox. The pressure controller is equipped with a second pressure sensor to prevent overpressurization of the glovebox if the differential pressure gauge fails.

Another safety feature to assure no over- or underpressurization of the inert gas filled and purged gloveboxes is the use of a dual passive bubbler that is connected to a glovebox port [20]. The bubblers are interconnected and filled with ethylene glycol to prevent both over- or under- pressurization of a glovebox. Typically, these devices are set to allow no more than +/15 mbar differential pressure across the glovebox boundary. The outlet of the bubbler is routed to the laboratory exhaust duct to allow appropriate venting of the glovebox in case of pressure excursion.

As illustrated in Figure 1, STAR is equipped with overhead and wall-mounted manifolds that facilitate the interconnection of the tritium gloveboxes and associated experiment and process equipment with the TCS inlet valves. This diagram shows the interconnection of the TCS with the SAS glovebox, two gloveboxes for molten salt experiments, a glovebox for future experiments and the TPE glovebox. A second manifold is used to interconnect the experiment and process equipment outlets(e.g., vacuum pump exhaust) to the corresponding input at the TCS.

\section{II.B.IV. Tritium Monitoring Systems}

Tritium monitoring instrumentation is installed in the STAR facility to measure tritium concentrations in room air, glovebox atmospheres, and the facility exhaust duct. Room air monitoring is accomplished with 2-L, flowthrough ion chambers that are equipped with auxiliary pumps and are connected to sampling manifolds to provide a real time measurement of tritium concentrations in the room air. These monitors, with a sensitivity of at least $1 \mu \mathrm{Ci} / \mathrm{m}^{3}$, are set to alarm at the tritium DAC level $\left(20 \mu \mathrm{Ci} / \mathrm{m}^{3}\right)$ to serve as a warning of airborne tritium in the environment occupied by workers. Each tritiumglovebox is equipped with an ion chamber and circulating pump to provide a measure of tritium concentrations in the glovebox atmosphere. These glovebox tritium monitors, with a sensitivity of $1 \mu \mathrm{Ci} / \mathrm{m}^{3}$, are set to alarm at set-points higher than the room air monitors and they serve to alert the worker of leaks or permeation losses in tritium primary containment hardware that contribute to higher than normal tritium concentrations in the glovebox. Based on glovebox monitor tritium levels, the worker can manage the purge gas flow rate through the glovebox and TCS to reduce the tritium concentration to acceptable levels.

STAR facility tritium releases to the environment are tracked via integral measurements with a Mound Technical Services Model MRB500 Bubbler/Collection Monitor. A stainless steel line is routed from this instrument to a sampling point downstream from the TRA-666 STAR facility HVAC exhaust blower. A pump inside the bubbler unit operates at $0.150 \mathrm{~L} / \mathrm{min}$ to sample a small fraction of the airflow in the exhaust duct. Nominal airflow rate in the exhaust duct is about $3.5 \times 10^{4}$ $\mathrm{L} / \mathrm{min}$. Outlet from the bubbler unit is connected to the laboratory exhaust duct inside Room 101. The MRB500 unit is equipped with two banks of ethylene glycol bubblers that, when used in conjunction with an internal Pd oxidizer bed, provides a measure of both elemental and oxide tritium concentrations in the laboratory exhaust stream. The bubbler unit operates continuously. Typically, the bubblers are changed weekly and tritium concentrations in the ethylene glycol are measured using Liquid Scintillation Counting (LSC). If a release is suspected, based on glovebox, experiment/process system or room air ion-chamber measurements, the bubbler vials are changed more frequently. This information, in combination with sampling time, sample flow rate through the bubbler and flow rate in the facility exhaust duct provides the means to quantify tritium stack releases from STAR. Test measurements have been done with a tritiated gas mixture to verify performance of the MRB500 bubbler unit. Tritium release tests are underway to calibrate the current "stack monitor" configuration for the MRB500 bubbler. 


\section{CONCLUDING REMARKS}

In this paper we have presented the following for the Safety and Tritium Applied Research Facility at the INEEL: (1) an overview of the capabilities to support a variety of fusion-relevant research activities in STAR and (2) a detailed description of the current status of development and implementation of the infrastructure for tritium operations in STAR. Major tritium infrastructure activities have been completed.

Ongoing work that will allow tritium operations to commence in the latter months of 2004 include the following: (1) calibration of stack monitor system with tritium release to the STAR exhaust, (2) in-situ calibration of the SAS beta scintillation detector with tritium, (3) completion of safety review and tritium operations documentation and (4) a management assessment review of proposed tritium operations. Concurrent with these activities is the continuing effort to complete the reassembly of the TPE system to allow high intensity plasma material interaction studies. Future plans also include characterization measurements for dust and codeposited layers from fusion devices and laboratory plasma systems and the setup of molten salt experiments that will incorporate tritium in their test plans.

\section{ACKNOWLEDGEMENTS}

This work was supported by the U.S. Department of Energy Office of Fusion Energy Sciences, under DOE Idaho Operations Contract DE-AC07-99ID13727.

\section{REFERENCES}

[1] R. A. Anderl, D. A. Petti and K. A. McCarthy, "The Safety and Tritium Applied Research (STAR) Facility," Fusion Science and Technology, 41, 568 (2002).

[2] DOE-HDBK-1129-99, "Tritium Handling and Safe Storage," US Department of Energy (1999).

[3] D. A. Petti and K. A. McCarthy, "Progress in US Fusion Safety and Environmental Activities over the past decade," Fusion Technology, 37, 1 (2000).

[4] R. A. Anderl, D. F. Holland, G. R. Longhurst, R. J. Pawelko, C. L. Trybus and C. H. Sellers, "Deuterium Transport and Trapping in Polycrystalline Tungsten," Fusion Technology, 21, 745 (1992).

[5] R. A. Anderl, R. J. Pawelko and S. T. Schuetz, "Deuterium Retention in W, W1\%La, C-coated W and $\mathrm{W}_{2} \mathrm{C}$, , J. Nuclear Materials, 290-293, 38 (2001).

[6] D. A. Petti, R. A. Anderl, G. R. Smolik, D.-K. Sze, T. Terai and S. Tanaka, "JUPITER-II Flibe Tritium/Chemistry and Safety Experimental Program," Fusion Science and Technology, 41, 807 (2002).
[7] R. A. Anderl et al., "Flibe Molten Salt Research for Tritium Breeder Applications," Proceedings of the $6^{\text {th }}$ IEA International Workshop on Beryllium Technology for Fusion, Miyazaki, Japan, December 2-5, 2003, JAERI-Conf 2004-006, p. 265, Japan Atomic Energy Research Institute (2004).

[8] G. Smolik et al., "Mobilization Measurements from Flibe Under Argon and Air Flow," J. Nuclear Materials, 329-333, 1322 (2004).

[9] R. A. Anderl et al., "Deuterium/Tritium Behavior in Flibe and Flibe-Facing Materials," J. Nuclear Materials, 329-333, 1327 (2004)

[10] R. A. Anderl, R. J. Pawelko, M. A. Oates, G. R. Smolik and K. A. McCarthy, "System for SteamReactivity Measurements on Fusion-Relevant Materials," Fusion Technology, 30, 1435 (1996).

[11] R. A. Anderl, R. J. Pawelko, G. Piazza, F. ScaffidiArgentina and L. L. Snead, "Steam oxidation of PFC Materials for Advanced Tokamaks," J. of Nuclear Materials, 307-311, 1375 (2002).

[12] J. P. Sharpe, V. Rohde, A. Sagara, et al., "Characterization of Dust Collected from ASDEXUpgrade and LHD," J. Nuclear Materials, 313, 455 (2003).

[13] J. P. Sharpe, D. A. Petti, H. W. Bartels, "A Review of Dust in Fusion Devices: Implications for Safety and Operational Performance," Fusion Engineering and Design, 63-4, 153 (2002).

[14] G. R. Smolik, D. A. Petti, J. P. Sharpe, et al., "Oxidation and Volatilization from Tantalum Alloy during Air Exposure," Fusion Technology, 39(2), 970 (2001).

[15] G. R. Smolik, R. J. Pawelko, R. A. Anderl, et al., "Oxidation and Volatilization from Tungsten Brush High Heat Flux Armor during Steam Exposure," Fusion Engineering and Design, 54(3-4), 583 (2001).

[16] PermaCon Modular Panel Containment Systems, NFSRPS Radiation Protection Systems, Groton, CT, USA.

[17] R. A. Causey et al., "Status and Future of the Tritium Plasma Experiment," Fusion Technology, 28 (3), 1144 (1995).

[18] R. Causey et al., "Tritium Retention in Tungsten Exposed to Intense Fluxes of $100-\mathrm{eV}$ Tritons," $J$. Nuclear Materials, 266, 467 (1999).

[19] G. R. Longhurst, R. A. Anderl, R. J. Pawelko, C. J. Stoots, "Storage and Assay of Tritium in STAR," this Conference.

[20] Health Physics Manual of Good Practices for Tritium Facilities, MLM-3719, pp 519-521, EG\&G Mound Applied Technologies (1991) 